\title{
RELEVÂNCIA DO ESTÁGIO CURRICULAR SUPERVISIONADO EM EDUCAÇÃO FÍSICA NA EDUCAÇÃO ESPECIAL PARA FORMAÇÃO DOCENTE
}

\author{
SIMÕES NETO, José de Caldas* \\ Faculdade Leão Sampaio - Juazeiro do Norte (CE), Brasil.
}

Recebido em: 05/01/2015; Aceito: 22/04/2015; Publicado: 25/08/2015

\begin{abstract}
RESUMO
No cenário educacional da sociedade contemporânea a formação de professores de Educação Física ganha espaço e destaque. Para que esta visão persista é necessária a efetivação da prática pedagógica com relação entre teoria e prática. Neste sentido, entendemos que o Estágio Curricular Supervisionado é a ferramenta de interação para o conhecimento teórico atuante na prática docente. O presente estudo tem com objetivo identificar os pontos relevantes do estágio curricular supervisionado em Educação Física na educação especial para a formação docente. A população considerada foram os acadêmicos do Curso de Licenciatura em Educação Física de uma Instituição de Ensino Superior do Estado do Ceará que realizaram o Estágio Curricular Supervisionado IV - Educação Especial, tendo uma amostra de dezessete acadêmicos. A partir da análise dos dados podemos considerar que o Estágio Curricular Supervisionado em Educação Física na Educação Especial, proporciona aos estagiários uma vasta experiência profissional no processo de formação acadêmica dos mesmos; o contato com os alunos com necessidades especiais insere valores para na vida pessoal e profissional. A convivência com os alunos especiais deixa bem claro que é preciso viver para conhecer as formas de trabalhar com a realidade de cada um. Na prática que se faz é possível perceber as adaptações estudadas na teoria muitas vezes não são adequadas, pois em uma mesma sala são encontrados alunos com necessidades diferentes, assim as adaptações devem ocorrer para cada aluno. A realização desse estágio é uma grande porta para a definição de um bom professor, possibilitando aos acadêmicos uma carga de conhecimento para seu futuro profissional e pessoal.
\end{abstract}

Palavras-Chave: Educação Física; Educação Especial; Estágio Curricular Supervisionado.

\begin{abstract}
In the educational scenario of contemporary society teacher training of Physical Education gains space and prominence to view persists that is required to effect the pedagogical practice in relation between theory and practice. In this sense, we believe that the Supervised interaction is the tool for the active teaching theoretical knowledge in practice. The present study has the objective to identify relevant points of the curriculum in supervised physical education in special education for teacher training. The population remained scholars of Bachelor of Physical Education, Faculty who underwent Supervised IV - Special Education, with a sample of seventeen academics. From the data analysis we can consider that the Supervised Physical Education in Special Education, interns provide extensive professional experience in the academic training of the same process; contact with students with special needs to enter values in personal and professional life. Living with the special students makes clear that we must live to know ways to work with the reality of each. In practice it is possible to perceive the adaptations studied in theory are often not appropriate because in the same classroom students with different needs, so adjustments must occur for each student are found. The completion of this stage is a major port for the definition of a good teacher, enabling a load of academic knowledge to their professional and personal future.
\end{abstract}

Keyword: Physical Education; Special Education; Supervised Internship. 


\section{INTRODUÇÃO}

No cenário educacional da sociedade contemporânea a formação de professores de Educação Física ganha espaço e destaque, para que está visão persista é necessária à efetivação da prática pedagógica com relação entre teoria e prática, almejando futuras perspectivas de sucesso na atuação profissional. Neste sentido, entendemos que o Estágio Curricular Supervisionado é a ferramenta de interação para o conhecimento teórico atuante na pratica docente.

A disciplina de Estágio Curricular Supervisionado é uma disciplina de cunho obrigatório para o Curso de Licenciatura em Educação Física de uma Instituição de Ensino Superior do Estado do Ceará, que é dividida em Estágio Supervisionado I, na educação infantil e/ou ensino fundamental $\mathrm{I}-1^{\circ}$ ano ao $5^{\circ}$ ano; Estágio Supervisionado II $-6^{\circ}$ ano ao $9^{\circ}$ ano, no ensino fundamental II; Estágio Supervisionado III, no ensino médio e Estágio Supervisionado IV, na Educação Especial, cada estágio com carga horária de $100 \mathrm{~h} / \mathrm{a}$ de regência em sala. Essa prática de estágio tendo como principal objetivo levar o aluno do curso de licenciatura em contato direto com seu campo de trabalho, aproximando-o da realidade das escolas e pessoas com quem irá trabalhar ao concluir sua graduação.

A Educação Especial é uma ramificação da educação que atende às pessoas com necessidades especiais, existindo instituições que atende alunos com necessidades especiais específicas como, escolas para pessoas com deficiências auditivas, visuais ou escola para pessoas com deficiência intelectual; outras instituições realizam o atendimento de múltiplas necessidades especiais como a Associação de Pais e Amigos dos Excepcionais (APAE's), e nas escolas regulares o atendimento é realizado pela sala do Atendimento Educacional Especializado (AEE), que atende o aluno matriculado no ensino regular para desenvolver suas habilidades e diminuir suas dificuldades específicas.

A LDB n 9394/96 no Art. 58º, entende a educação especial como "a modalidade de educação escolar, oferecida preferencialmente na rede regular de ensino, para educandos portadores de necessidades especiais" (BRASIL, 1996). No Brasil existe um plano de Política Nacional de Educação Especial na Perspectiva da Educação Inclusiva desde 2008, onde busca a integração das pessoas com necessidades especiais estejam engajadas no ensino regular.

A Educação Física Adaptada é uma das formas de integração das pessoas com necessidades especiais nas escolas. $\mathrm{Na}$ sala de aula o aluno com necessidades especiais realiza todas as atividades $\mathrm{e}$ trabalhos propostos em sala, participa das aulas e debates. Já nas aulas de Educação Física, os alunos muitas vezes são dispensados, ficando exclusos das aulas. Com a Educação Física Adaptada o aluno com necessidade especial pode ser incluso e sua deficiência não será um empecilho. Através das aulas surgirá uma nova concepção do seu corpo e de suas capacidades, pois o espaço estará aberto para ele participar e se descobrir. Desde modo esse trabalho tem como objetivo identificar os pontos relevantes do estágio curricular supervisionado em Educação Física na educação especial para a formação docente (CARDOSO; BASTILHA, 2010).

Justifica-se a presença do professor de Educação Física na educação especial para os alunos com necessidades especiais, porque através das aulas o professor proporcionará aos alunos atividades motoras, cognitivas e sócio-afetivas, como também a construção de atitudes desenvolvendo o respeito, aceitação e 
solidariedade. Para Oliveira (2002), o professor deve oportunizar os seus alunos para o desenvolvimento de suas potencialidades, especialmente os alunos com necessidades educacionais especiais, para que desse modo consigam interagir com si próprio e com os demais alunos.

A partir dos estudos e vivências da área podemos levantar a problemática: Qual a relevância da regência na educação especial para a formação docente de professores de Educação Física?

Sendo idealizado como hipótese do estudo, que o Estágio Curricular Supervisionado em Educação Física na Educação Especial oportuniza aos acadêmicos o contado com os diversos conteúdos aplicados aos alunos da educação especial, como também o contato e convívio com os alunos e demais profissionais das instituições e pessoas das comunidades envolvidas no campo de estágio, levando a uma formação rica de saberes.

\section{REFERENCIAL TEÓRICO}

\subsection{LEGISLAÇÃO EDUCACIONAL: EDUCAÇÃO FÍSICA}

A primeira Lei promulgada na legislação educacional onde consta a disciplina de Educação Física foi a Lei de Diretrizes e Bases da Educação Nacional, Lei $\mathrm{N}^{\circ}$ 9.394, de 20 de dezembro de 1996 que estabelece as diretrizes e bases da educação no Brasil. A Educação Física já era tratada como obrigatória nos cursos de primeiro grau e médio, até a idade de 18 anos, onde a concepção era formar jovens fisicamente fortes, viris e produtivos para ingressar no mercado de trabalho (BRASIL, 1996).

Essa lei vem para abranger o processo formativo da vida familiar, em sua convivência humana, trabalho e nas instituições de ensino e pesquisa, como também em movimentos sociais e manifestações culturais.

A reforma educacional no ano de 1971 veio determinar casos específicos para participação na disciplina de Educação Física: no período noturno, ter mais de 30 anos de idade, estar prestando serviço militar e estar fisicamente incapacitado. Com essas normas podemos verificar que a prática da Educação Física era voltada para a formação do trabalhador, forma que o governo utilizava a disciplina para fins governamentais intencionalmente (BRASIL, 1996).

Para Silva e Venâncio (2005, p. 55), o descaso para com a disciplina desde essa época é notado devido:

A Educação Física não ser uma disciplina, e sim, uma mera atividade extracurricular. Isto fez com que ela fosse vista como um elemento sem comprometimento formativo educacional.

A partir da promulgação da lei n ${ }^{\circ}$ 9394/96 (Lei de Diretrizes e Bases da Educação Nacional) o status da Educação Física mudou, passando a ser considerada um componente curricular como qualquer outro. A referida legislação reza em seu artigo 26 (parágrafo 3), o seguinte:

A Educação Física integrada à
proposta pedagógica da escola é
componente curricular da
Educação Básica, ajustando-se às
faixas etárias e às condições da
população escolar, sendo
facultativa nos cursos noturnos
(SILVA; VENÂNCIO, 2005, p.
55).

A partir de então muito foi feito para que a Educação Física fosse obrigatória, como também, para uma melhor condição e preparação dos profissionais da área, pois durante muitos anos, leigos e militares ministravam essa disciplina de forma equivocada. Em 1998 no dia 01 de Setembro o então Presidente da República Fernando Henrique Cardoso, regulamenta na Lei $\mathrm{n}^{\circ} 9696$ a regulamentação da Profissão de Educação Física e 
cria os respectivos Conselho Federal e Conselhos Regionais de Educação Física (BRASIL, 1998).

Segundo a Lei $\mathrm{n}^{\circ}$ 9696/98 no artigo terceiro trata das competências aos Profissionais de Educação Física:

Compete ao Profissional de Educação Física coordenar, planejar, programar, supervisionar, dinamizar, dirigir, organizar, avaliar e executar trabalhos, programas, planos e projetos, bem como prestar serviços de auditoria, consultoria e assessoria, realizar treinamentos especializados, participar de equipes multidisciplinares e interdisciplinares e elaborar informes técnicos, científicos e pedagógicos, todos nas áreas de atividades físicas e do desporto (BRASIL, 1998, s/p).

Sobre a importância da Educação Física na escola, segundo a Sacristán e Gómez (2000, p. 14), é de grande valia, por seus conteúdos, suas formas e seus sistemas de organização, a escola proporciona aos alunos, paulatina e progressivamente, a apropriação de idéias, conhecimentos, concepções, disposições e modos de conduta que a sociedade adulta requer. As escolas são atualmente as instituições que na sociedade, exercem o papel fundamental de transmitir valores entre as gerações.

Diante da importância da disciplina de Educação Física no âmbito escolar a Lei n ${ }^{\circ} 10.328$ de 12 de dezembro de 2001, introduz a palavra "obrigatório" após a expressão "curricular", constante do $\S 3^{\circ}$ do art. 26 da Lei $n^{\circ} 9.394$, de 20 de dezembro de 1996, que estabelece as diretrizes e bases da educação nacional. (BRASIL, 2001, s/p)

A Educação Física compõe o currículo do ensino fundamental ao ensino médio aborda uma parte diversificada nos aspectos regionais e locais da sociedade, da cultura, da economia e da clientela. Dessa forma deve estar integrada a proposta pedagógica da escola, sendo que a sua prática seja facultada ao aluno:
I - que cumpra jornada de trabalho igual ou superior a seis horas;

$$
\begin{aligned}
& \text { II - maior de trinta anos de idade; } \\
& \text { III - que estiver prestando serviço militar }
\end{aligned}
$$
inicial ou que, em situação similar, estiver obrigado à prática da Educação Física;

IV - amparado pelo Decreto-Lei no 1.044, de 21 de outubro de 1969;

$$
\begin{aligned}
& \mathrm{V} \text { - (VETADO) } \\
& \mathrm{VI} \text { - que tenha prole. }
\end{aligned}
$$

Lei no 10.793 , de $1^{\circ}$ de dezembro de 2003 , que altera a redação do art. $26, \S 3^{\circ}$ da Lei no 9.394 , de 20 de dezembro de 1996, que estabelece as diretrizes e bases da educação Nacional (BRASIL, 2003, s/p).

Em 2006 é homologada mais uma Lei que se refere à Educação Física. O então Presidente da República Luiz Inácio Lula da Silva, decreta e sanciona a seguinte Lei $\mathrm{n}^{\circ}$ 11.342, de 18 de Agosto de 2006, que dispões sobre o Dia do Profissional de Educação Física. “Art. $1^{\circ}$ Fica instituído o dia $1^{\circ}$ de setembro como o Dia do Profissional de Educação Física" (BRASIL, 2006, s/p). Ficando como dia para a comemoração do dia do Professor de Educação Física em razão de a profissão ter sido regulamentada através da Lei federal de número 9.696/98 e publicada na mesma data, nesse dia os professores de Educação Física organizavam brincadeiras para divertir-se (BRASIL, 1998).

2.2

ESTÁGIO

CURRICULAR

\section{SUPERVISIONADO EM EDUCAÇÃO FÍSICA}

A Educação Física é de grande influência na formação e faz parte das ações de desenvolvimento dos valores do ser humano. Para que os Professores de Educação Física estejam preparados para a vida profissional no mercado de trabalho devem passar por etapas de fortalecimento e preparação durante o processo de formação, 
portanto, o Estágio Curricular Supervisionado é a etapa inicial da formação. Segundo o parecer $n^{\circ}$ 21/2001 alterado pelo parecer $\mathrm{m}^{\circ} 28$ do Conselho Nacional de Educação - CNE do ano de 2001, que trata de estabelece a duração e a carga horária dos cursos de Formação de Professores da Educação Básica, em nível superior, curso de licenciatura, de graduação plena (BRASIL, 2001).

O parecer do CNE $n^{\circ} 28 / 2001$ trata o Estácio Curricular Supervisionado como:

[...] estágio curricular supervisionado de ensino entendido como o tempo de aprendizagem que, através de um período de permanência, alguém se demora em algum lugar ou ofício para aprender a prática do mesmo e depois poder exercer uma profissão ou ofício. Assim o estágio curricular supervisionado supõe uma relação pedagógica entre alguém que já é um profissional reconhecido em um ambiente institucional de trabalho e um aluno estagiário (BRASIL, 2001, p. 10).

Conforme a LDB 9394/96 no seu art. 13, os profissionais da educação: docentes deverão vivenciar da vida escolar de um modo geral, desde atividades de elaboração de proposta pedagógica da escola, até elaboração e cumprimento de planos de trabalho, seguido de atividades, como zelo pela aprendizagem do aluno, estabelecimento de estratégias de recuperação para alunos de menor rendimento, participação nos períodos de planejamento, avaliação e desenvolvimento profissional e a colaboração em atividades de articulação da escola com as famílias e a comunidade (BRASIL, 1996).

\section{3 \\ ESTÁGIO \\ CURRICULAR}

SUPERVISIONADO NO CURSO DE

EDUCAÇÃO FÍSICA DE UMA INSTITUIÇÃO

DE ENSINO SUPERIOR DO ESTADO DO

CEARÁ
A disciplina de Estágio Curricular Supervisionado é uma disciplina de cunho obrigatório para o Curso de Licenciatura em Educação Física de uma Instituição de Ensino Superior do Estado do Ceará. O qual é dividido em Estágio Supervisionado I, no ensino infantil e ensino fundamental I; Estágio Supervisionado II, no ensino fundamental II; Estágio Supervisionado III, no ensino médio e Estágio Supervisionado IV, na Educação Especial, cada um com carga horária de 100h/a em campo, sendo 10 horas de observação e 90 horas de regência de sala; os estágios só poderão ser realizados em Escolas/Instituições da Zona Urbana, nas cidades de Crato, Juazeiro e Barbalha, com no máximo 12 horas semanais.

Os estágios são regulamentados na instituição pelas Normas de Ética, conduta profissional e cumprimento dos Estágios Supervisionados para estudantes de Educação Física de uma Instituição de Ensino Superior do Estado do Ceará, onde para realização dos estágios, as normas são:

Artigo $1^{\mathrm{o}}$ : Somente poderão realizar o Estágio Curricular Supervisionado os alunos que:

I - estiverem regulares na matrícula e frequência;

II - assinarem o termo de compromisso entre o estudante, a parte concedente do estágio e a instituição de ensino;

III - apresentar compatibilidade entre as atividades desenvolvidas no estágio e aquelas previstas no termo de compromisso;

IV - Terem sido aprovados nas disciplinas pré-requisitos.

O estágio IV é aplicado na educação especial e/ou instituições de atendimento a pessoas com necessidades especiais e instituições de Educação Básica com Atendimento Educacional Especializado (AEE) devidamente regulamentada. 
As competências que regem o Estágio Curricular Supervisionado na Educação Especial segundo as Normas de Ética e Conduta de uma Instituição de Ensino Superior do Estado do Ceará para o Curso de Educação Física são:

\section{Título VIII: DAS COMPETÊNCIAS}

Ao acadêmico/ estagiário das disciplinas de estágios supervisionados compete:

I - Cumprir as etapas previstas para a realização do estágio, a saber:

a - observação do campo de estágio

b - participação/colaboração na regência de classe

c - atuação na regência de aulas nas respectivas instituições

d - realizações das atividades previstas para a disciplina

e - registro das atividades desenvolvidas

f - elaboração de relatório final

II - discutir com o professor regente de classe o planejamento e a execução das atividades propostas;

III - manter um comportamento compatível com a função docente, pautando-se pelos princípios da ética profissional;

IV - avaliar de modo constante e crítico o seu desempenho na função docente;

V - colaborar para a solução de problemas na escola, campo de estágio e com seus colegas de turma;

VI - comunicar com antecedência sua ausência nas atividades previstas;

VII - cumprir integralmente as normas estabelecidas no regulamento de estágio supervisionado.

VIII - No Estágio IV o acadêmico/estagiário deverá apresentar um projeto de atuação ao professor regente da disciplina (conforme modelo entregue pelo mesmo na primeira semana de aula) antes de iniciarem no campo de estágio e logo após a apresentação da Carta de Apresentação na instituição concedente. Os acadêmicos deverão apresentar o Projeto juntamente com o ofício na instituição concedente. VIV - Ao término do Estágio IV, os acadêmicos estagiários devem entregar uma cópia do relatório final definitivo na instituição concedente e, anexar no relatório final a ser entregue para a professora regente da disciplina uma declaração assinada pelo professor colaborador afirmando o recebimento da cópia.

\subsection{EDUCAÇÃO ESPECIAL E EDUCAÇÃO FÍSICA: RELAÇÃO TEORIA E PRÁTICA NO ESTÁGIO CURRICULAR SUPERVISIONADO}

As instituições que atendem, pessoas com necessidades especiais, deve ser uma equipe de profissionais diversificados, para suprir todas as necessidades de seus alunos, atingido todos os objetivos de melhorar a qualidade de vida das pessoas com necessidades especiais. Portanto, é possível observar nessas instituições a reunião de diferentes áreas de intervenção profissional, dentre elas a Educação Física, com o intuito de elevar a qualidade do serviço por elas ofertado (GLAT; FERNANDES, 2005).

O caráter multidisciplinar presente nessa intervenção profissional pode ser considerado, em larga medida, conseqüência da complexidade que envolve a oferta de serviços para pessoas com necessidades especiais. Nesse cenário, cada profissional que participa da equipe de profissionais da Fisioterapia, Psicologia, Pedagogia, Serviço Social e Educação Física, deve ter claro o objetivo e as delimitações de sua intervenção dentro das instituições nas quais atuam. A equipe de profissionais da instituição trabalha em união buscando desenvolver todas as habilidades motoras, 
intelectuais e sócio-afetivas dos alunos (FEIJÓ, 2006).

Para Sassaki (1997), incluir significa preparar-se para receber a pessoa com necessidade especial na sociedade, ou seja, dar oportunidades iguais na escola, no trabalho, na saúde, no lazer, no esporte, oferecer livre acesso e independência, respeitando as leis e os direitos do ser humano em geral.

$\mathrm{Na}$ Educação Física e no esporte, este fenômeno não é diferente. Em se tratando de atividade física para pessoas com necessidades especiais, é preciso sensibilizar a sociedade sobre isso, afirma Winnick (2004), essas pessoas podem vencer barreiras com o seu próprio eu e através disso, conquistar grandes feitos. Além da sensibilização social e a prática inclusiva poderão favorecer as pessoas ditas normais, que, para Sassaki (1997), correm o risco de tornarem-se mais solidárias e mais humanas. Para Duarte e Lima (2003, p. 95), "deve passar pela queda de um muro: o do preconceito, que mutila e debilita qualquer processo de crescimento".

Oportunizar os alunos com necessidade especiais de vivências, problemas e desafios engrandece o seu pensar sobre si e o mundo ao seu redor. As aulas de Educação Física devem ser planejadas e propostas de maneira diversificada, possibilitando aos alunos que terão contato com o mundo e suas regras. De acordo com os Parâmetros Curriculares Nacionais (1997, p. 41), a aula de Educação Física pode: favorecer a construção de uma atitude digna e de respeito próprio por parte do deficiente e a convivência com ele pode possibilitar a construção de atitudes de solidariedade, de respeito, de aceitação, sem preconceitos (BRASIL, 1997).

O professor deve trabalhar os conteúdos da Educação Física para as pessoas com necessidade especiais como trabalha com os alunos regulares. $\mathrm{O}$ professor deve selecioná-los de acordo com os Parâmetros Curriculares Nacionais (BRASIL, 1997, p. 47), que são: "esportes, jogos, lutas, ginástica, atividades rítmicas e expressivas e conhecimento sobre o corpo", seguindo e enfatizando do mesmo modo do ensino regular; proporcionando a aprendizagem que mobilize os aspectos afetivos, sociais e éticos; instigar a participação de todos.

O Estágio Curricular Supervisionado permite aos acadêmicos, o envolvimento $\mathrm{e}$ vivências, a relação entre a teoria e a prática no processo de formação docente. Proporciona a realização do exercício da profissão e aperfeiçoa consideravelmente as ações pedagógicas.

No contexto pedagógico, a teoria é considerada a idéia de ordenamento e sistematização dos conhecimentos, o conjunto de conceitos sobre o real para ser aplicado na prática. A prática é o saber fazer, baseado no que se aprendeu na teoria. Sem a teoria as ações da prática seriam obscuras e sem objetividades, passando somente a idéias abstratas e sem sentido (TARDIF, 2014).

Segundo Winterstein apud Ghilardi (1998, p. 6) "a teoria sem a prática é oca, a prática sem a teoria é cega". Portanto, na medida em que se complementam a teoria e a prática, são duas faces de uma mesma moeda, onde se a teoria separa-se da prática, torna-se subjetivismo.

A interação entre ambas, teoria/prática, proporciona um avanço no aprendizado, a dialética a respeito da teoria aliada à prática faz que o processo de aprendizado possa ocorrer com facilidade. Segundo Freire (1996, p. 12) “ensinar não é transferir conhecimento, mas criar as possibilidades para a sua produção ou a sua construção". Para cada relação na área profissional da educação deve-se procurar posicionamento teórico, sendo esclarecidos os papéis de educador e educando, como a teoria e prática devem ser 
compreendidas como uma unidade de reciprocidade.

É primordial que a teoria e a prática sejam trabalhadas em conjunto, tecendo o conhecimento de uma forma efetiva e real, pois este processo vem de encontro com os novos rumos que a Educação Física tem tomado na atualidade, é preciso que o Estágio Curricular Supervisionado dê suporte para que os futuros professores possam partilhar de outras formas de se fazer Educação Física e que esta se torne mais atuante e dinâmica entre os alunos.

\section{METODOLOGIA}

A presente pesquisa é de caráter descritivo, com enfoque qualitativo e quantitativo. A pesquisa descritiva apresenta como instrumento para a coleta de dados questionários e entrevistas, tendo em vista conhecer aspectos de uma população determinada. A pesquisa qualitativa, "considera que há uma relação dinâmica entre o mundo real e o sujeito, isto é, um vínculo indissociável entre o mundo objetivo e a subjetividade do sujeito que não pode ser traduzido em números"; e uma parte quantitativa, "considera que tudo pode ser quantificável, o que significa traduzir em números opiniões e informações para classificá-las e analisá-las (MORESI, 2003, p. 8 e 9).

A população foi composta pelos acadêmicos do Curso de Licenciatura em Educação Física de uma Instituição de Ensino Superior do Estado do Ceará que realizaram o Estágio Curricular Supervisionado IV - Educação Especial do período de 2011.1 e 2011.2, tendo a Amostra 17 acadêmicos.

A coleta de dados foi realizada junto aos acadêmicos do Curso de Educação Física de uma Instituição de Ensino Superior do Estado do Ceará, mediante uma ficha de identificação e um questionário com perguntas objetivas e subjetivas, elaboradas e aplicadas pelo autor da pesquisa, com questões sobre a relevância do Estágio Curricular Supervisionado em Educação Física na educação especial para formação docente e assinaram o Termo de Consentimento Livre e Esclarecido (TCLE).

\section{RESULTADOS E DISCUSSÃO}

Durante a coleta de dados foi possível verificar a abrangência de instituições que desenvolvem trabalhos com o público com necessidades especiais, onde aparecerão sete instituições em Juazeiro do Norte, sendo seis escolas e uma APAE, uma instituição em Crato, a APAE.

Isso mostra a abrangência do campo no mercado de trabalho, onde existe carência em todas as regiões e localidades e que as pessoas com necessidades especiais estão amparadas dentro dessas instituições e que as políticas públicas voltadas a essa área estão efetivas e em plena atuação.

No processo de ensino-aprendizagem a Educação Física atua dentro dos aspectos motores, sociais e afetivo, de acordo com os Parâmetros Curriculares Nacionais, implica na forma em que se planeja, em que se experimenta e em que se avalia; como coordena as ações de movimento do corpo no objeto do tempo e espaço; como interage com as outras pessoas e integra-as na sociedade com objetivo de inclusão e igualdade, com um ensino de aprendizagem qualificada, favorecendo todas as pessoas que dela participam (BRASIL, 1997).

A Educação Física faz com que as crianças fiquem bastante expostas: nos jogos, brincadeiras, desafios corporais e em diversas outras atividades, onde assim os professores podem observar onde as crianças possuem dificuldades e habilidades. Por conta disso, os Parâmetros Curriculares Nacionais, 
citam que é de extrema importância que se tenha o maior cuidado com as discriminações e estigmatizações que possam ocorrer. Não podemos excluir um aluno somente por ele ter algum tipo de necessidade especial, pensar que ele não é capaz e sim dá oportunidade para ele se conhecer e superar suas limitações, e ampliar suas habilidades (BRASIL, 1997).

Por tudo isso os acadêmicos devem estar preparados para atuação nessa área com muitos subsídios teóricos, para já na prática possa exercer sua função de maneira correta e proporcionar que os alunos atinjam os objetivos na melhoria da sua qualidade de vida para cada necessidade que necessite melhorar, seja ela motora, intelectual, afetiva ou social.

Para Sassaki (1997), incluir significa preparar-se para receber a pessoa portadora de deficiência na sociedade, ou seja, dar oportunidades iguais na escola, no trabalho, na saúde, no lazer, no esporte, oferecer livre acesso e independência, respeitando as leis e os direitos do ser humano em geral.

Segundo a figura 01 abaixo podemos verificar o nível de aquisição de conhecimentos dos acadêmicos durante uma vida acadêmica para uma atuação adequada no estágio curricular supervisionado na educação especial.

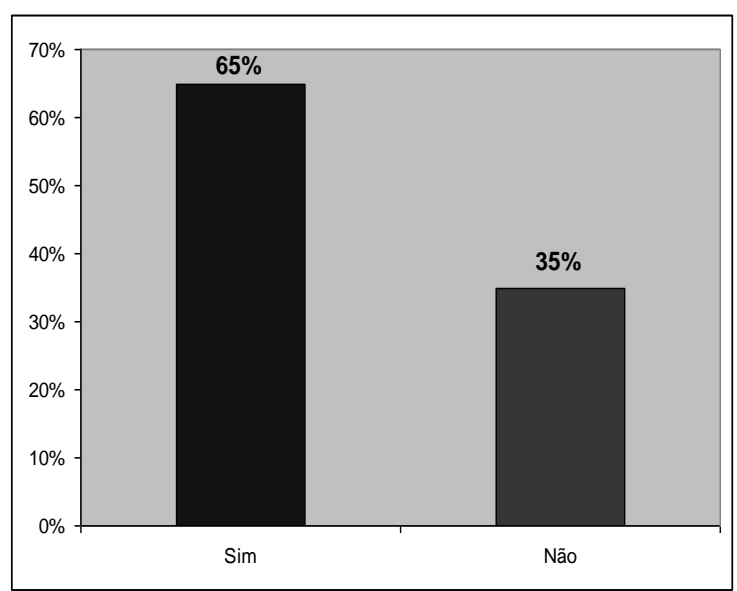

Figura 01: Conhecimentos Pedagógicos adquiridos na formação foram suficientes para o Estágio Curricular Supervisionado na Educação Especial.

Fonte: Dados da Pesquisa,
Segundo a figura 01 verificamos que $65 \%$ dos acadêmicos consideraram que os conhecimentos adquiridos durante sua formação acadêmica foram suficientes para uma boa atuação no estágio na educação especial. Já $35 \%$ não consideraram os conhecimentos adquiridos na sua formação suficientes para atuação na educação especial.

A figura 02, que trata da relação Teoria e Prática vivenciada de forma efetiva no Estágio Curricular Supervisionado na Educação Especial.

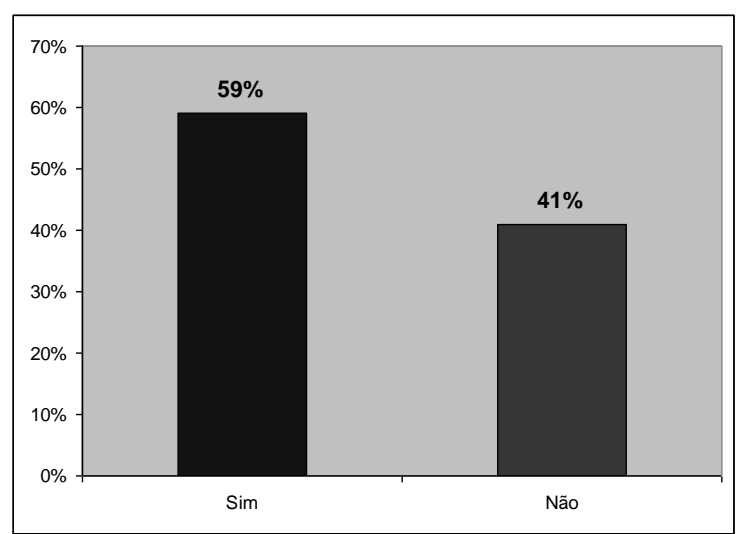

Figura 02: Estágio Curricular Supervisionado na Educação Especial - Relação entre a Teoria e Prática de forma efetiva.

Fonte: Dados da Pesquisa,

Podemos verificar que 59\% dos acadêmicos relatam que o estágio proporcionou uma vivência conforme a teoria em suas práticas.

Já $41 \%$ dos acadêmicos não consideraram uma vivência de forma efetiva da relação entre teoria e prática, pois muitas vezes em uma única turma encontravam-se alunos com deficiências diferentes sendo necessário adaptar as atividades várias vezes.

Segundo a análise do sujeito coletivo para o questionamento sobre o que o Estágio Curricular Supervisionado na Educação Especial pode ter oferecido para a sua formação Profissional, podemos destacar que, os acadêmicos poderão amadurecer para enfrentar novos desafios e batalhas, perceber a realidade real da prática 
pedagógica e que os estudos são sempre necessários para uma boa atuação seja qual for à área.

$\mathrm{Na}$ Educação Física e no esporte, este fenômeno não é diferente. Em se tratando de atividade física para pessoas portadoras de deficiência, é preciso conscientizar a sociedade sobre isso, afirma Winnick (2004), essas pessoas podem vencer barreiras com o seu próprio eu e através disso, conquistar grandes feitos.

Em relação ao questionamento do que poderia ser aperfeiçoado no Estágio Curricular Supervisionado na Educação Especial, os relatos puderam concluir que deve haver mais interação entre estagiários, professores das instituições e professores supervisores com o objetivo de melhor interação e desenvolvimento das atividades no campo de estágio, para amenizar as aflições dos acadêmicos perante a realidade do campo em relação à teoria.

Desenvolver ações para fiscalização do cumprimento das leis na Educação Especial, sendo incluindo essa ação como forma de avaliação na construção de um documento para a instituição de ensino onde se realiza o estágio como também uma devolutiva de toda a experiência vivida no campo de estágio para gerar subsídios às instituições da realidade com os seus diretos juntos às leis e determinações já estabelecidas pelas políticas públicas.

Finalizando as discussões devemos lembrar que, o professor deve trabalhar os conteúdos da Educação Física junto às pessoas com necessidades especiais como trabalha com os alunos regulares.

\section{CONSIDERAÇÕES FINAIS}

O Estágio Curricular Supervisionado em Educação Física na Educação Especial proporciona aos estagiários uma vasta experiência profissional no processo de formação acadêmica dos mesmos, o contato com os alunos com necessidades especiais insere valores para na vida pessoal e profissional. Há diferenças em todas as pessoas sejam ditas "normais" ou com necessidades especiais, o contato com alunos especiais deixa bem claro que todos são capazes de realizar qualquer atividade. Podemos perceber que no estágio curricular na educação especial os acadêmicos vêem diferenças entre teoria e prática. A convivência com os alunos especiais deixa bem claro que é preciso vivenciar para conhecer as formas de trabalhar com a realidade de cada um. Somente com as práticas nas aulas de Educação Física, que se faz possível perceber as adaptações estudadas na teoria muitas vezes não são adequadas, pois em uma mesma sala são encontrados alunos com necessidades diferentes, assim as adaptações devem ocorrer para cada aluno.

A realização desse estágio nas instituições com a modalidade de educação especial é uma grande porta para a definição da formação de um bom professor, possibilitando aos acadêmicos uma carga de conhecimento para seu futuro profissional e pessoal.

\section{REFERÊNCIAS}

BRASIL, Lei de Diretrizes e Bases da Educação Nacional. Lei n 9394, de 20 de dezembro de 1996.

Parâmetros Curriculares Nacionais (PCNs): Educação Física. 2 ed. Secretaria de Educação Fundamental. Rio de Janeiro, 1997.

Parâmetros Curriculares Nacionais (PCNs): Educação Física. 2 ed. Secretaria de Educação Fundamental. Rio de Janeiro: DPSA, 2000.

Introduz a palavra "obrigatório" após a expressão "curricular", constante do § 3o do art. 26 da Lei de Diretrizes e Bases da Educação Nacional. Lei no 10.328 , de 12 de dezembro de 2001. 
Mensagem de veto da Lei de Diretrizes e Bases da Educação Nacional. Lei no 10.793, de $1^{\circ}$ de dezembro de 2003.

Dispõe sobre o Dia do Profissional de Educação Física. Lei $\mathrm{n}^{\mathrm{o}} 11.342$, de 18 de agosto de 2006.

BRAYNER, P.R.P. et al. Normas de Ética, Conduta Profissional e Cumprimento dos Estágios Supervisionados para Estudantes de Educação Física da Faculdade Leão Sampaio. Faculdade Leão Sampaio, Juazeiro do Norte Ceará, 2011.

CARDOSO, V. D.; BASTILHA, R. R. Inclusão de alunos com necessidades especiais na escola: reflexões acerca da Educação Física Adaptada. Revista EFdesportes, Buenos Aires - Ano 15 - $\mathrm{N}^{\mathrm{o}}$ 146 - Julio de 2010. Disponível em: http://www.efdeportes.com/efd146/inclusao-dealunos-com-necessidades-especiais.htm

DUARTE, E.; LIMA, S. T. Atividades Físicas para Pessoas com Necessidades Especiais. Rio de Janeiro: Guanabara Koogan, 2003.

FEIJÓ, G. O. et al. Equipe multiprofissional na escola especial: a educação física em questão. Revista EFdesportes, Buenos Aires n. 103, p. 25, $2006 . \quad$ Disponível em: http://www.efdeportes.com/efd103/multip.htm

FREIRE, P. Pedagogia da Autonomia: Saberes Necessários à Prática Educativa. Editora Paz e Terra, São Paulo, 1996.

GLAT, R.; FERNANDES, E. M. Da educação segregada à educação inclusiva: uma breve reflexão sobre os paradigmas educacionais no contexto da educação especial brasileira. Revista Inclusão, v. 1, n. 1, p. 35-39, 2005.

GHILARDI, R. Formação profissional em Educação Física: a relação teoria e prática. Universidade São Judas Tadeu, Motriz - Volume 4, Número 1, São Paulo, 1998. Disponível em: http://www.rc.unesp.br/ib/efisica/motriz/04n1/4n1 ART01.pdf

MORESI. E. Metodologia da Pesquisa. Universidade Católica de Brasília - UCB, Brasília DF, 2003.

OLIVEIRA, F. F. Dialogando sobre educação, Educação Física e inclusão escolar. Revista Digital - Buenos Aires - Ano 8 - N 51, 2002.
SACRISTÁN, J. G; GÓMEZ, A. I. P. Compreender e transformar o ensino. 4. ed. Porto Alegre, Editora Artmed, 2000.

SASSAKI, R. K. Inclusão: Construindo uma sociedade para todos. Rio de Janeiro: WVA, 1997.

SILVA, E.V.M. VENÂNCIO, L. Aspectos legais da Educação Física e integração à proposta pedagógica da escola. In: DARIDO, S.C.; RANGEL, I.C.A. (Coord.) Educação Física na escola: implicações para a prática pedagógica. Rio de Janeiro: Guanabara Koogan, 2005.

TARDIF, M. Saberes docentes e formação profissional. Editora Vozes Limitada, 2014.

WINNICK, J. Educação Física e Esportes Adaptados. Trad. Fernando Augusto Lopes. 3. ed. São Paulo: Manole, 2004. 